\title{
Telogen Effluvium after SARS-CoV-2 Infection: A Series of Cases and Possible Pathogenetic Mechanisms
}

\author{
Alfredo Rossi Francesca Magri Alvise Sernicola Simone Michelini \\ Gemma Caro Marta Muscianese Marco Di Fraia Camilla Chello \\ Maria Caterina Fortuna Teresa Grieco \\ Dermatology Unit, Department of Clinical Internal, Anesthesiological and Cardiovascular Sciences, \\ Sapienza University of Rome, Rome, Italy
}

\section{Established Facts}

- Evidence of telogen effluvium (TE) in the setting of coronavirus disease 2019 is currently limited to isolated reports.

- Increase in hair loss has been reported in infected patients during the 2014-2015 dengue epidemic.

- Potent pro-inflammatory and antiviral responses are potential inducers of TE.

\section{Novel Insights}

- We report 14 cases of new-onset acute coronavirus disease 2019 (COVID-19) telogen effluvium (TE) occurring between 1 and 3 months after severe acute respiratory syndrome coronavirus 2 (SARS$\mathrm{CoV}-2)$ infection.

- While trichoscopic features and trichogram showed no variations from classice TE, time to onset was shorter in COVID-19 TE.

- Early onset after SARS-CoV-2 infection hints at direct viral damage to hair follicles in COVID-19 TE.

\section{Keywords}

Coronavirus disease 2019 · Hair loss · Hair microscopy ·

Telogen effluvium · Trichoscopy

\section{Abstract \\ Introduction: Physicians have largely studied the cutaneous involvement of coronavirus disease 2019 (COVID-19), but}

only few reports have focused on telogen effluvium (TE) as a possible sequela of COVID-19. We assessed 14 cases of hair loss occurring after SARS-CoV-2 infection using trichoscopy and trichogram to investigate patterns related to COVID-19. Furthermore, we discussed possible mechanisms involved in COVID-19 TE. Case Presentation: Fourteen individuals were referred to our post-COVID-19 dermatology office complaining acute hair loss after SARS-CoV-2 infection. Clinical evalu- karger@karger.com www.karger.com/sad
(C) 2021 S. Karger AG, Basel
Correspondence to:

Alvise Sernicola, alvise.sernicola@uniroma1.it

Karger 
ation included pull test, trichoscopy, and trichogram. COVID-19 TE occurred after a median of 2 months (range 1-3 months) following SARS-CoV-2 infection. The median duration of hair loss was 5 months (range 1-6 months). Trichoscopy showed variable but typical TE patterns. Trichogram showed different telogen/anagen ratio depending on the interval between onset of hair loss and trichological visit. Discussion/Conclusion: Our cases showed TE between 1 and 3 months after the onset of SARS-CoV-2 infection, thus earlier than classic TE. Trichoscopic features and trichogram showed no variations from classic TE. Different pathogenetic mechanisms including pro-inflammatory cytokines and direct viral damage on the hair follicle can be hypothesized; further studies on a larger sample are needed to better understand this condition.

(c) 2021 S. Karger AG, Basel

\section{Introduction}

Severe acute respiratory syndrome coronavirus 2 (SARS-CoV-2) is the causative pathogen of coronavirus disease 2019 (COVID-19), which has rapidly spread across the globe from December 2019 until today, causing the current pandemic [1]. Though the most common symptoms are fever, malaise, dry cough, and pneumonia, clinicians have focused on the recognition of cutaneous involvement in the course of COVID-19. Cutaneous signs, including chilblain-like, maculopapular, and vesicular lesions, urticaria, livedoid/necrotic lesions, are frequently reported, but their classification is debated.

Telogen effluvium (TE), first described by Kligman in 1961 [2], is a diffuse, non-scarring shedding of hairs, resulting from the early entry of the hair into the telogen phase. Classic TE is self-limited and acute, defined as lasting less than 6 months, and occurs approximately 3-4 months after a triggering event. Moreover, a chronic form of TE is reported, exceeding 6 months of duration. Several agents have been associated with TE, including drugs, physiological stress (surgery and high fever), emotional stress, chronic infections, dietary and iron deficiency, and smoking.

The aim of our work was to assess hair loss occurring after SARS-CoV-2 infection using trichoscopy and trichogram to investigate possible patterns related to COVID-19 in 14 subjects. Furthermore, we discussed possible disease mechanisms that may be involved in COVID-19 TE.

\section{Case Presentation}

Between August and November 2020, 14 individuals were referred to the post-COVID-19 office of our dermatology unit complaining acute hair loss initiating 1-3 months after the onset of SARS-CoV-2 infection. All cases were diagnosed with positive RTPCR on nasopharyngeal swab. Demographic and clinical characteristics of each patient are summarized in Table 1. Median age of our sample was 49 years (range 23-64 years). Twelve patients were females, while 3 were males. Ten out of 14 patients were not hospitalized, and the remaining 4 had ordinary hospitalization. Two individuals were totally asymptomatic, while symptoms presented by the other patients are reported in Table 1. COVID-19 TE occurred in our group after a median of 2 months (range 1-3 months) following the onset of SARS-CoV-2 infection. The median duration of hair loss was 5 months (range 1-6 months), with subsequent partial or total resolution of the hair loss.

After collecting patient history, all 14 patients were clinically evaluated, and then pull test, trichoscopy, and trichogram were performed. Global photographs (shown in Fig. 1a) and trichoscopic pictures were systematically taken at the vertex and frontal region, with a medicam 800 video-dermatoscope (FotoFinder Systems $\mathrm{GmbH}$, Bad Birnbach, Germany). Hair shafts for trichogram were harvested approximately $2 \mathrm{~cm}$ above the ear from the parietal region, which is not an androgenetic alopecia area. Trichogram was performed by grasping 30-50 hairs with a hemostat covered with rubber and cutting hair shafts $1 \mathrm{~cm}$ above the root sheaths. Roots were then arranged side by side and taped. Trichoscopy showed variable but typical TE patterns, such as regrowing hairs, follicular units with 1 hair, empty hair follicles (HFs), and thin terminal hairs (shown in Fig. 1b).

Trichogram showed different telogen/anagen ratio depending on the distance between the onset of hair loss and the trichological visit (shown in Fig. 1c, d). Trichograms showed a telogen rate of $20 \%$ or less in 6 subjects who presented to our clinic after over 3 months from the beginning of hair loss. However, personal history, evidence of shedding, and trichoscopic observation of regrowing hair supported a diagnosis of TE in regression. For the same reason, pull test resulted positive in 7 individuals and negative in 7 patients. In particular, 4 subjects who were hospitalized for COVID-19 were assessed between 3 and 5 months after onset of hair shedding and consequently showed clinical presentations consistent with TE in regression. This prevented us from hypothesizing a correlation between the severity of SARS-CoV-2 infection and that of TE. All patients were prescribed daily oral supplementation containing alpha-lipoic acid, calcium pantothenate (vitamin B5), vitamin D3, biotin, and ferrous gluconate for 3 months. Cases of active TE were also instructed to topically apply clobetasol propionate $0.05 \%$ foam 3 times a week for 3 months. Patients are currently undergoing follow-up at our outpatient clinic.

\section{Discussion}

According to our observations, COVID-19 TE occurred earlier than classic acute TE. Our cases showed hair loss between 1 and 3 months after the onset of SARSCoV-2 infection, while in classic TE, this is usually ob- 
Table 1. Description of 14 patients with post-COVID-19 TE

\begin{tabular}{|c|c|c|c|c|c|c|c|c|c|c|c|c|}
\hline $\begin{array}{l}\text { Patient } \\
\text { No. }\end{array}$ & Sex & $\begin{array}{l}\text { Age, } \\
\text { years }\end{array}$ & $\begin{array}{l}\text { Time } \\
\text { to } \\
\text { onset }^{\dagger}\end{array}$ & $\begin{array}{l}\text { Dura- } \\
\text { tion }^{\ddagger}\end{array}$ & COVID-19 symptoms & $\mathrm{H}$ & $\begin{array}{l}\text { Therapy for } \\
\text { COVID-19 }\end{array}$ & $\begin{array}{l}\text { Skin and } \\
\text { adnexal signs }\end{array}$ & $\begin{array}{l}\text { Previous } \\
\text { scalp } \\
\text { disorders }\end{array}$ & $\begin{array}{l}\text { Pull } \\
\text { test }\end{array}$ & $\begin{array}{l}\text { Trichos- } \\
\text { copy } \\
\text { patterns } \$\end{array}$ & Trichogram \\
\hline 2 & $\mathrm{~F}$ & 23 & 1 & 6 & $\begin{array}{l}\text { Anosmia, dysgeusia, } \\
\text { fever, diarrhea, asthenia }\end{array}$ & - & PCM & $\begin{array}{l}\text { Defluvium, } \\
\text { itching, } \\
\text { eyelid edema }\end{array}$ & I & - & 1 & $\begin{array}{l}80 \% \text { anagen, } \\
20 \% \text { telogen }\end{array}$ \\
\hline 5 & $\mathrm{~F}$ & 60 & 1 & 5 & $\begin{array}{l}\text { Fever, diarrhea, } \\
\text { dysgeusia, dry cough }\end{array}$ & + & $\begin{array}{l}\text { HCQ, AZI, CTX, } \\
\text { DRV + COBI }\end{array}$ & Defluvium & Previous SD & - & 1 & $\begin{array}{l}74 \% \text { anagen, } \\
26 \% \text { telogen }\end{array}$ \\
\hline 6 & F & 41 & 2 & 5 & Fever, dry cough & - & PCM, ABX & Defluvium & l & - & 1 & $\begin{array}{l}80 \% \text { anagen, } \\
20 \% \text { telogen }\end{array}$ \\
\hline 7 & M & 36 & 2 & 4 & Mild fever & - & PCM & Defluvium & l & + & $1 ; 2 ; 3$ & $\begin{array}{l}55 \% \text { anagen, } \\
45 \% \text { telogen }\end{array}$ \\
\hline 10 & M & 49 & 2 & 4 & Fever & - & PCM & Defluvium & AGA & + & $1 ; 2 ; 3$ & $\begin{array}{l}55 \% \text { anagen, } \\
45 \% \text { telogen }\end{array}$ \\
\hline 11 & $\mathrm{~F}$ & 50 & 2 & 3 & Asymptomatic & - & No therapy & Defluvium & AGA & + & $1 ; 2 ; 3$ & $\begin{array}{l}70 \% \text { anagen, } \\
30 \% \text { telogen }\end{array}$ \\
\hline 12 & $\mathrm{~F}$ & 62 & 1 & 1 & Fever & - & PCM & Defluvium & l & + & 4 & $\begin{array}{l}46 \% \text { telogen, } \\
64 \% \text { anagen }\end{array}$ \\
\hline 13 & $\mathrm{~F}$ & 43 & 2 & 3 & Dry cough & - & ABX, steroids & Defluvium & l & + & $3 ; 5$ & $\begin{array}{l}30 \% \text { telogen, } \\
70 \% \text { anagen }\end{array}$ \\
\hline 14 & M & 34 & 2 & 5 & Asymptomatic & - & No therapy & Defluvium & AGA & - & $3 ; 5$ & $\begin{array}{l}82 \% \text { anagen, } \\
18 \% \text { telogen }\end{array}$ \\
\hline
\end{tabular}

ABX, other antibiotics; AGA, androgenetic alopecia; AZI, azithromycin; CTX, ceftriaxone; COVID-19, coronavirus disease 2019; DRV + COBI, darunavir + cobicistat; F, female; HCQ, hydroxychloroquine; H, hospitalization; LVX, levofloxacin; M, male; PCM, paracetamol; PPZ, pantoprazole; SD, seborrheic dermatitis; TCZ, tocilizumab; TE, telogen effluvium. ${ }^{\dagger}$ Time to onset of TE was calculated in months from the first symptoms of COVID-19 to the initiation of hair loss. For asymptomatic patients 11 and 14, this time was calculated from the date of positive RT-PCR test, which was performed within 10 days of close personal contacts with a certain case of infection. ${ }^{\ddagger}$ Duration in months. ${ }^{\S}$ Described trichoscopic patterns are as follows: 1 , terminal and regrowing hairs; 2 , follicular units with 1 hair; 3 , empty follicles; 4 , diffuse empty follicles; 5 , regrowing hairs.

Fig. 1. Post-COVID-19 TE. Macroscopic images of a patient showing partial resolution of acute TE (a); trichoscopic image showing several regrowing thin hairs and terminal hairs and some follicular units with 1 hair, $\times 30($ b); trichogram with $26 \%$ telogen hairs and $74 \%$ anagen hairs (c); telogen hairs (d). COVID-19, coronavirus disease 2019; TE, telogen effluvium.
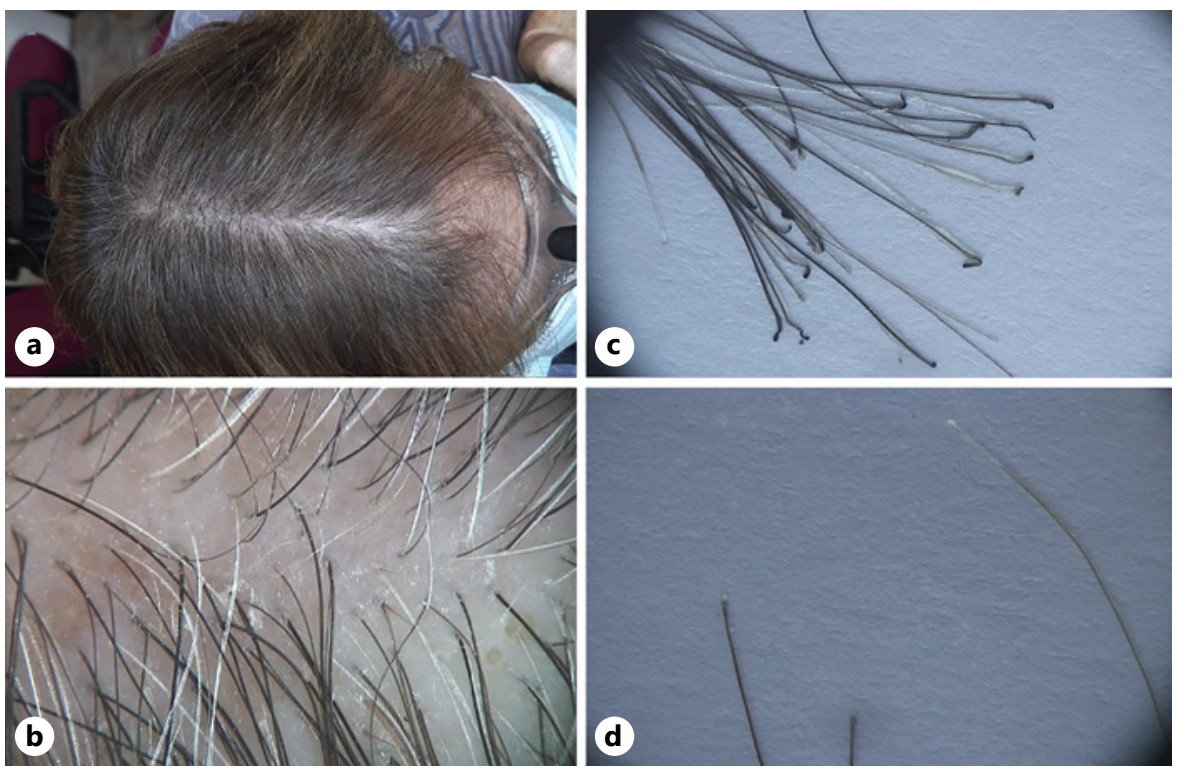
served after 3-4 months. On the other side, trichoscopic features and trichogram results in our patients showed no variations from classic TE. Evidence of TE in the setting of COVID-19 is currently limited and consists in a few reports.

Rivetti et al. [3] reported an exacerbation of hair loss during the Italian quarantine of March 2020 in 25 patients already affected by TE, associating the worsening of TE to the psychological stress connected to the lockdown conditions. In another study conducted using a webbased questionnaire, TE was recorded in $27.9 \%$ of 563 individuals, probably as a consequence of mental distress [4]. Domínguez-Santás et al. [5] were the first to report a case of acute TE, occurring 3 months after SARS-CoV-2 infection, and have been followed by additional authors, who described TE after COVID-19 [6, 7].

Common pathogenetic mechanisms occurring in COVID-19 TE may be hypothesized. First of all, acute TE may be induced by the intense release of pro-inflammatory cytokines as a consequence of viral infections. SARS$\mathrm{CoV}-2$ and other viruses elicit strong antiviral responses, especially via interferon, which is a well-known TE-inducer molecule. Recombinant interferon alpha-2b therapy has similarly been reported to induce TE [8]. Interleukin (IL)-6 is a pro-inflammatory cytokine; it has a key role in severe COVID-19. High levels of IL-6 act on the HF, inducing the catagen phase as well as causing local inflammation and collapse of the immune privilege. It has been shown that high levels of IL-4, which are typical of COVID-19 in the elderly, also determine keratinocyte apoptosis in HF [9]. Additional molecules showing high levels in COVID-19 are metalloproteinases 1 and 3 and IL-1 $\beta$, which may inhibit the HF growth [10], and the immunosuppressive cytokine IL-10, which apparently does not have direct effects on the follicular units.

Moreover, direct viral damage to HFs may be hypothesized in COVID-19 TE owing to the early onset of TE after SARS-CoV-2 infection. SARS-CoV-2 is characterized by superficial spike glycoproteins, which bind angiotensin I-converting enzyme-2 on host cells, allowing pathogen entry. Additional entry mechanisms include antibody-dependent enhancement (ADE), which is due to the presence of non-neutralizing virus-specific antibodies (NAb). NAbs are present in patients with SARS$\mathrm{CoV}-2$ infection and are able to promote virus entry into host cells through interaction with $\mathrm{Fc} \gamma$ and/or complement receptors [11]. We hypothesized that SARS-CoV-2 may determine direct effects on the HF via the ADE phenomenon as previously reported for dengue virus. During the 2014-2015 dengue epidemic, an increase in hair loss had been reported in infected patients. Studies demonstrated that the HF dermal papilla cells, which express Fc receptors, are susceptible to the virus and attributed the mechanism of infection to the ADE phenomenon [12]. Other than in dengue virus infection, ADE phenomenon has also been documented in coronaviruses, including SARS-CoV and Middle East Respiratory Syndrome Coronavirus (MERS-CoV) [13].

Finally, it is speculative whether androgens and their receptor, which regulate the HF cycle and have a key role in TE, could facilitate a direct effect of SARS-CoV-2 on the HF. According to our observations, therapies administered for COVID-19 in our patients or psychological distress was unlikely a trigger of hair loss, since the timing of onset of TE is not compatible with drug-related or stress-related TE, which commonly occurs 3-4 months after the triggering event.

\section{Conclusion}

In conclusion, we reported 14 cases of new-onset acute COVID-19 TE occurring between 1 and 3 months after SARS-CoV-2 infection. We hypothesized different pathogenetic mechanisms, including release of pro-inflammatory cytokines and direct viral damage on the HF; however, further studies on a larger sample are needed to improve current understanding of this condition.

TE is increasingly reported in the setting of COVID-19, and physicians should be made aware of this possible sequela [14]. Furthermore, in the current era of pandemic, we suggest that a SARS-CoV-2 infection should be suspected and investigated in a patient who presents with acute TE.

\section{Statement of Ethics}

The present research was conducted ethically in accordance with the World Medical Association Declaration of Helsinki. All subjects have given their written informed consent to publish their case, including publication of images.

\section{Conflict of Interest Statement}

The authors have no conflicts of interest to declare.

\section{Funding Sources}

The authors have received no external funding. 


\section{Author Contributions}

All authors contributed to drafting the work and revising it critically and approved the final version of the manuscript. A.R.: conceptualization and writing - review and editing. F.M.: data curation and writing - original draft. A.S.: data curation and writ- ing - review and editing. S.M.: investigation and writing - review and editing. G.C.: supervision and writing - original draft. M.M.: methodology and supervision. M.D.F.: investigation and writing - review and editing. C.C.: investigation and writing - review and editing. M.C.F.: methodology and supervision. T.G.: validation and writing - review and editing.

\section{References}

1 Daneshgaran G, Dubin DP, Gould DJ. Cutaneous manifestations of COVID-19: an evidence-based review. Am J Clin Dermatol. 2020 Oct;21(5):627-39.

2 Klingman A. Pathologic dynamics of human hair loss. I. Telogen effluvium. Arch Dermatol. 1961 Feb;83:175-98.

3 Rivetti N, Barruscotti S. Management of telogen effluvium during the COVID-19 emergency: psychological implications. Dermatol Ther. 2020 Jul;33(4):e13648.

4 Turkmen D, Altunisik N, Sener S, Colak C. Evaluation of the effects of COVID-19 pandemic on hair diseases through a web-based questionnaire. Dermatol Ther. 2020 Nov; 33(6):e13923.

5 Domínguez-Santás M, Haya-Martínez L, Fernández-Nieto D, Jiménez-Cauhé J, Suárez-Valle A, Díaz-Guimaraens B. Acute telogen effluvium associated with SARSCoV-2 infection. Aust J Gen Pract. 2020 Aug 26;49:49.
6 Mieczkowska K, Deutsch A, Borok J, Guzman AK, Fruchter R, Patel P, et al. Telogen effluvium: a sequela of COVID-19. Int J Dermatol. 2021 Jan;60(1):122-4.

7 Giulio R, Federico D, Anna C, Radi G, Bianchelli T, Molinelli E, et al. Telogen effluvium related to post severe Sars-Cov-2 Infection: clinical aspects and our management experience. Dermatol Ther. 2021 Jan;34(1): e14547.

8 Tosti A, Misciali C, Bardazzi F, Fanti PA, Varotti C. Telogen effluvium due to recombinant interferon alpha-2b. Dermatology. 1992; 184(2):124-5.

9 Mandt N, Geilen CC, Wrobel A, Gelber A, Kamp H, Orfanos CE, et al. Interleukin-4 induces apoptosis in cultured human follicular keratinocytes, but not in dermal papilla cells. Eur J Dermatol. 2002 Sep-Oct;12(5):432-8.

10 Xiong Y, Harmon CS. Interleukin-1beta is differentially expressed by human dermal papilla cells in response to $\mathrm{PKC}$ activation and is a potent inhibitor of human hair follicle growth in organ culture. J Interferon Cytokine Res. 1997 Mar;17(3):151-7.
11 Ulrich H, Pillat MM, Tárnok A. Dengue fever, COVID-19 (SARS-CoV-2), and antibody-dependent enhancement (ADE): a perspective. Cytometry A. 2020 Jul;97(7):662-7.

12 Wei KC, Huang MS, Chang TH. Dengue virus infects primary human hair follicle dermal papilla cells. Front Cell Infect Microbiol. 2018 Aug;8:268.

13 Karthik K, Senthilkumar TMA, Udhayavel S, Raj GD. Role of antibody-dependent enhancement (ADE) in the virulence of SARS$\mathrm{CoV}-2$ and its mitigation strategies for the development of vaccines and immunotherapies to counter COVID-19. Hum Vaccin Immunother. 2020 Dec 1;16(12):1-6.

14 Trüeb RM, Dutra Rezende H, Gavazzoni Dias MFR. What can the hair tell us about COVID-19? Exp Dermatol. 2021 Feb;30(2):28890. 